\section{CASE OF EGG BOUND CONDITION IN AN INDIAN PEAFOWL (PAVO CRISTATUS)}

\author{
Kazveen D. Umrigar \\ Bondla Zoo, Goa Forest Department, P.O. Usgaon, Goa 403407, \\ India.
}

A Peahen (Pavo cristatus) was found lying recumbent on her side in the enclosure, at Peshwe Park Zoo, Pune. She was unable to stand even with support and offered no resistance to examination and handling. The bird was anorectic and dull. As the hen was in the middle of her clutch period, an X-ray was taken to confirm the possible diagnosis of egg binding. Quite surely the egg was visible in the X-ray, just near the cloaca.

Treatment of egg binding was carried out as prescribed in Ritchie et al. (1994). A dab of Ceriviprime gel (Dinoprostone $0.5 \mathrm{mg}$, Astra Zeneca) was applied intra-cloacally as the prescribed dose of Dinoprostone in birds is 0.02 to $0.1 \mathrm{mg} / \mathrm{kg}$. Dinoprostone (a prostaglandin) stimulates the gravid uterus to cause evacuation of the uterine contents. Injection of $2 \mathrm{ml}$ Calborol (Calcium boro-gluconate) was administered subcutaneously and oral tube feeding of fruit juices and multivitamin syrup was carried out as supportive care.

By next morning the hen had laid the egg but was unable to stand or show any motor or sensory reflexes in both legs. Presumably, the egg might have exerted pressure or caused slight damage to the sciatic nerves (during its passage through the oviduct) leading to transient paralysis / paresis. As the bird was in no position to feed itself, the bird was tube-fed thrice a day with liquidized fruits and spinach (Using Rompson's feeding tube no.7). Multi-vitamins and selenium were administered orally with Vi-Syneral (USV) and Ambiplex (Brihans) syrups; 40ml Ringer's lactate solution (subcutaneously) and $1 \mathrm{ml}$ Neurobion Injection (Merck) (intramuscularly) were injected. The bird started showing signs of improvement and recovered completely in 10 days, when the above treatment was discontinued and the bird was put back in her enclosure.

\section{Acknowledgement}

I thank Dr. S. Gokhale, Gokhale Hospital Pune, for providing Xray facilities.

\section{Reference}

Ritchie B.W., G.J. Harrison and L.R. Harrison (editors) (1994) Avian Medicine: Principles and Application. Wingers.

Received 10 September 2003

Finally accepted 10 October 2003

\section{NEUROCYTICERCOSIS (CEREBRAL CYSTICERCOSIS) IN A CHIMPANZEE (PAN TROGLODYTES)}

\author{
Utkarsh Shukla \\ Zoo veterinarian and Deputy Director, Lucknow Zoological Garden, \\ Lucknow, Uttar Pradesh, India.
}

A male Chimpanzee (Pan troglodytes) aged about fourteen years died in Lucknow Zoo at $0520 \mathrm{hr}$ on 28 February 2002. The animal was at the Zoo since he was a two-month old. The present paper deals with the observation and detection of tapeworm infection in the animal.

The animal appeared quite normal even ten days before his death and had a normal routine diet. But suddenly from 17 February 2002 he showed periodic episodes of symptoms such as drowsiness, dizziness, dullness, hallucination, and staggering gait often with aversion to normal diet. He was unable to sit or stand properly and often laid down flat on the ground loosing partially his control on voluntary action. The animal was kept under keen observation, medical supervision and treatment from 17 February 2002 until his death.

Preliminary laboratory blood tests, chest and abdominal X-ray studied before his death were found normal except raised E.S.R. On postmortem examination many nodular cysts were found on the surface of the diaphragm, heart and lungs. On opening the cranium, the whole surface of the brain was found embedded with multiple cysts (27 in number) of tapeworm larvae (Taenia spp.) i.e. cysticercosis of variable size. The longitudinal section of few of these have shown that the cysts were filled with fluid and had an invaginated scolex with hooklets. Some areas of the brain of the Chimpanzee also revealed calcification.

Hardly any report of neurocyticercosis with multiple cysts particularly in Chimpanzee is available in literature. The astonishing factor of this case is the cause of infestation which is still a mystery as the animal is purely herbivorous and no non-vegetarian food was given to the animal at any time, and the intermediate host of Taenia is cattle or pig. Accidental contamination of the food could be a reason.

Received 21 July 2003

Finally accepted 1 October 2003 